
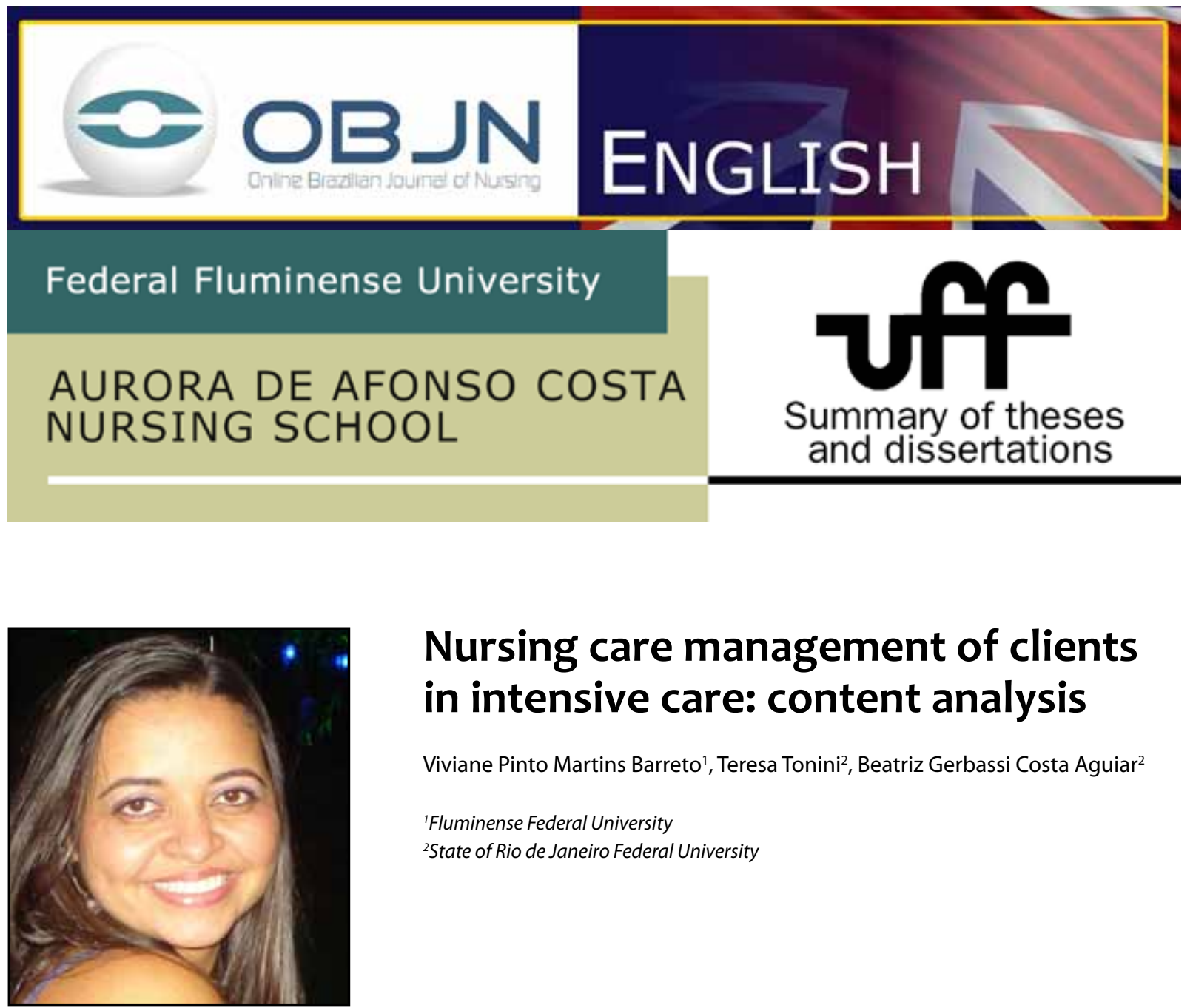

\title{
Nursing care management of clients in intensive care: content analysis
}

\author{
Viviane Pinto Martins Barreto' ${ }^{1}$ Teresa Tonini², Beatriz Gerbassi Costa Aguiar² \\ 'Fluminense Federal University \\ 2 State of Rio de Janeiro Federal University
}

\begin{abstract}
Aims: To identify the management process of the nurse in directly caring for the hospitalized client in an intensive care unit; to characterize how the work process of the intensive care nurse guides the caring provided to the client and; to discuss the management process of direct care of the work performed by the intensive care nurse. Method: This is a descriptive study based on a qualitative approach, undertaken with 16 nurses. To collect the information, we used a semi-structured interview, non-participative observation and a field journal. The results were later categorized and submitted to content analysis based on Bardin's principles.

Results: The nurse has two guiding axes to his actions: the mind map and the real map. The designs done on the mind map start from a single point, with the information radiating from this central point. However, when implementing management processes that were planned mentally, nurses generate a real map based on which they know how to perform.
\end{abstract}

Conclusion: In caring management, the nurse sees himself connected with the client, even though the professional does not get involved with direct care tasks.

Keywords: Nurse, Care Management, Intensive Care. 


\section{INTRODUCTION}

This study addresses the direct care management performed by nurses with regard to patients in an Intensive Care Unit (ICU). We observe that the development of the nurse in direct care management is one which maintains a certain distance from the client, as such a professional prefers to be involved in indirect care management during their working shift. It seems that there is a delegation of direct care roles to the other members of the team under the responsibility of the nurse. The management duties of the nurse in clinical practice are based on the bureaucratic and formal necessities of the organization ${ }^{(1)}$. In this process, the professional honors and allies herself closely with the organizational objectives, which may clash with the fulfillment of the individual goals of coworkers and clients may lead to a mismatch that builds tensions, demotivates staff and creates disharmony in the work environment.

\section{AIMS}

1- To identify the management processes of the nurse regarding the direct care of the client hospitalized in an intensive care unit; 2To characterize how the work processes of the intensive care nurse guides the caring provided to the intensive care clients; 3 - To discuss the management processes of direct care in terms of the work done by the intensive care nurse to the hospitalized client in an intensive care unit.

\section{METHOD}

This is a qualitative research, using a descriptive approach, developed in an $\mathrm{UCl}$ and in a Cardiac Unit of a Federal University Hospital in the city of Rio de Janeiro. Sixteen nurses were interviewed between May and June 2008. The results were organized and analyzed according to Bardin's(2) content analysis, from which the synthesis-skeleton was built in order to discuss the results. This research was approved by the Ethics Committee under registration CAAE 0030.0.258.000.08.

\section{RESULTS}

There are two guiding axes, both of which can be classified as cartographies of the management process in nursing, denominated as mental map and real $\operatorname{map}^{(3)}$. Mental maps exist in the brain, each part being associated with the rest, creating connections between the concepts of planning, intervention and evaluation in terms of nursing care related to the management of human resources, supplies, equipment and time. A real map relates to the tasks themselves, and involves direct care, indirect care and bureaucratic roles. Separate from the map, the client is the caring object of the nurse under the "well cared" principle.

\section{DISCUSSION}

The nurse recognizes himself as close to the client when performing indirect care roles, once this professional supervises the work done by his team. With the focus on the client during the work processes, the nurse guides his actions based on the seriousness of the clinical state of the client, in order to evaluate the extent to which each client needs care, to establish the competence and the schedule of those who are taking care of a specific client, to establish the space to be used and the time consumed in caring, and then, identifying the moment of intervention. The most significant characteristic of the client in intensive care is the severity of injury or illness and the imminent risk of death, demanding a know-how and decision-making skills on the part of the intensive care nurse to allow her to carefully evaluate and observe the necessities/demands of the client; to take speedy actions where necessary; to understand completely the whole technological apparatus. The last skill is a complex one because it is based on soft technology that transforms the nurse as someone involved in direct care into someone 
who can enrich the subjective healthcare process for the patient ${ }^{(4,5)}$. Nurses dominate a culture that is supported by temporary moments of care. Time can be considered as a culture and treated as a principle that organizes the tasks, the priorities and the supplies to cope with (un)expected situations. In a mind map, ideas and tasks are ordered based on concrete data from the shifts, the monthly schedule and the supplies/equipment available for the management of macro and indirect care. Thus, this management acknowledges the need to cope with continuous tasks with full commitment, perseverance and obstinacy so that they do not fail. However, the existing discontinuities in the management process that may have started due to poor working conditions, justify the obstinate behavior that leads to an apparent distancing of the nurses from direct contact. The real map refers to the guidance, supervision and evaluation of the client and nursing team, a direct care of the client, and bureaucratic actions. The nurse perform such tasks not only as someone who has to deal with such actions, but as a qualified professional, who evaluates the client as a whole, diagnoses the client's needs, performs nursing interventions and interacts with other professionals involved in the care of the client, to the extent of fulfilling all the needs reported by the client. Despite the fact that there is little direct contact, the nurse still focuses on the client. When there is the delegation of tasks and attributions, the nurse supervises the care service provided. However, there is a need to observe the limit of attributions transferred to the nursing technicians when in contact with the client.

\section{CONCLUSION}

In the management of nursing care, which aims to ensure a well-cared for client, the nurse sees himself as being close to the client, despite the fact that the professional no longer performs direct care roles. Therefore, there is a valuation of care planning for the client who may be in a critical state, and a recovery of the primary concept of caring, in order to offer the most adequate working conditions.

\section{REFERENCES}

1. Trevizan MA, Mendes IAC, Shinyashiki GT, Gray G. Nurses' management in the clinical practice: problems and challenges in search of competence. Rev Latino-Am Enfermagem. June 2006; 14(3):457-60.

2. Bardin L. Análise de conteúdo. Lisboa: Edições 70; 2008.

3. Triboli EPR. Mapas Mentais: uma introdução. São Caetano do Sul: Escola de Engenharia Mauá; 2004.

4. Figueiredo NMA, Carvalho V. O Corpo da Enfermeira como instrumento do cuidado. Rio de janeiro: Revinter; 1999.

5. Tonini T. Enfermeira instituída/instituinte: a subjetividade das estratégias de cuidar. Rio de Janeiro. Tese [Doutorado em medicina social] Universidade do Estado do Rio de Janeiro; 2006.

Date of Dissertation Defense: Rio de Janeiro, March $29^{\text {th }} 2009$

Examiners: Prof. Beatriz Gerbassi Costa Aguiar PhD, Prof. Antônio Marcos Tosoli Gomes PhD, Prof. Teresa Tonini PhD, Prof. Josete Luzia Leite PhD, Prof. Sônia Regina de Souza PhD

Bibliographical Reference: Barreto, VPM. A gerência do cuidado prestado pelo enfermeiro a clientes internados em terapia intensiva [Dissertação]. Rio de Janeiro (RJ), Brasil: Universidade Federal do Estado do Rio de Janeiro, 2009.

Received: 20/10/2012

Revised: 25/03/2013

Approved: 28/03/2013

Viviane Pinto Martins Barreto: data collection; literature review; interpretation and analysis; organization of the article in accordance with the standards of the journal and final approval of the article.

Teresa Tonini: data collection; literature review; interpretation and analysis; organization of the article in accordance with the standards of the journal and final approval of the article.

Beatriz Gerbasi Costa Aguiar: literature review and e organization of the article in accordance with the standards of the journal 